\title{
Flat-Band in Pyrochlore Oxides: A First-Principles Study
}

\author{
Izumi Hase ${ }^{1, * \mathbb{B}}$, Takashi Yanagisawa ${ }^{1}$ and Kenji Kawashima ${ }^{2}$ \\ 1 National Institute of Advanced Industrial Science and Technology (AIST), Tsukuba 305-8568, Japan; \\ t-yanagisawa@aist.go.jp \\ 2 IMRA Material R\&D Co. Ltd., Kariya 448-0032, Japan; kenji.kawashima@aisin.co.jp \\ * Correspondence: i.hase@aist.go.jp; Tel.: +81-29-861-5147
}

Received: 20 May 2019; Accepted: 7 June 2019; Published: 10 June 2019

\begin{abstract}
Using a first-principles electronic band calculation, we obtained a quasi flat-band near the Fermi level for the six pyrochlore oxides, $\mathrm{A}_{2} \mathrm{~B}_{2} \mathrm{O}_{7}$. These quasi flat-bands are mostly characterized by the s-orbitals of the A-site. The band structures of these oxides are well described by the non-interacting Mielke model. Spin-polarized calculations showed that the ground state of these compounds was ferromagnetic after appropriate carrier doping, despite the absence of the magnetic element.
\end{abstract}

Keywords: pyrochlore oxide; band calculation; flat band; ferromagnetism

\section{Introduction}

Magnetic oxides have been studied at length, and are of great importance from both the scientific and applied standpoint. They include Mn-perovskites, hexaferrites [1-10], and so on. Among them, pyrochlore oxides denoted by $\mathrm{A}_{2} \mathrm{~B}_{2} \mathrm{O}_{7}$ (or $\mathrm{A}_{2} \mathrm{~B}_{2} \mathrm{O}_{6} \mathrm{O}^{\prime}$ ) have been given much attention due to their rich variety of physical properties [11,12]. Most of the 150 or more kinds of pyrochlore oxides have been explored, and most have open-shell d-orbitals and f-orbitals on the A-site or the B-site. Usually, these orbitals are localized and only have spin degree of freedom. Since both of the A-sublattice and B-sublattice in $\mathrm{A}_{2} \mathrm{~B}_{2} \mathrm{O}_{7}$ are geometrically frustrated, these localized spins on the frustrated sublattice (i.e., pyrochlore lattice) bring about many exotic magnetic properties such as spin-ice, quantum spin liquid, and even a "magnetic monopole" [13-17]. There is another type of pyrochlore oxide, $\mathrm{Cd}_{2} \mathrm{Re}_{2} \mathrm{O}_{7}$, that shows superconductivity [18,19]. In $\mathrm{Cd}_{2} \mathrm{Re}_{2} \mathrm{O}_{7}$, the d-orbitals form itinerant bands, contrary to the above-mentioned localized d- (or f-) orbital system. In this paper, we studied the third type of pyrochlore oxides, which do not include relevant d- or f- orbitals. In particular, we focused on compounds with the relevant bands composed of s-orbitals of the A-site. At first glance, this type of pyrochlore oxide seems to be quite trivial due to the absence of strong correlation on the $\mathrm{d}$ - or $\mathrm{f}$ orbitals, but in fact, may show many interesting properties. When we only considered one s-orbital on each site of the pyrochlore lattice, and only considered the nearest-neighbor transfer $(t)$, it gave the (non-interacting) Mielke model described by the following Hamiltonian:

$$
H_{0}=-t \sum_{<i, j>\sigma} c_{i \sigma}^{\dagger} c_{j \sigma}
$$

where $c_{i \sigma}$ denotes the annihilation operator at $i$-th site with spin $\sigma$, and $\langle i, j\rangle$ denotes nearest neighbors. We can directly diagonalize this Hamiltonian in momentum space [20] and obtain the energy eigenvalues as

$$
E_{1,2}=-2 t\left[1 \pm \sqrt{1+A_{k}}\right], E_{3,4}=2 t
$$

where $A_{k}=\cos \left(2 k_{x}\right) \cos \left(2 k_{y}\right)+\cos \left(2 k_{y}\right) \cos \left(2 k_{z}\right)+\cos \left(2 k_{z}\right) \cos \left(2 k_{x}\right)$. The energy bands $E_{3,4}$ do not depend on the wave vector $k$ and are called flat-bands (FBs). Since the density of states (DOS) of 
FB is singular, this model gives many anomalous physical properties. In fact, FBs are seen in many lattice models [21,22], and vigorous studies have predicted that many attractive physical properties such as exact ferromagnetism [23,24], high-temperature superconductivity [25], various topological states [20,26], and the fractional quantum Hall effect [27] will be developed. Therefore, it is very important to find real materials that are approximately described by the FB model. Figure 1 shows the correspondence between the localized spin system and the itinerant system.

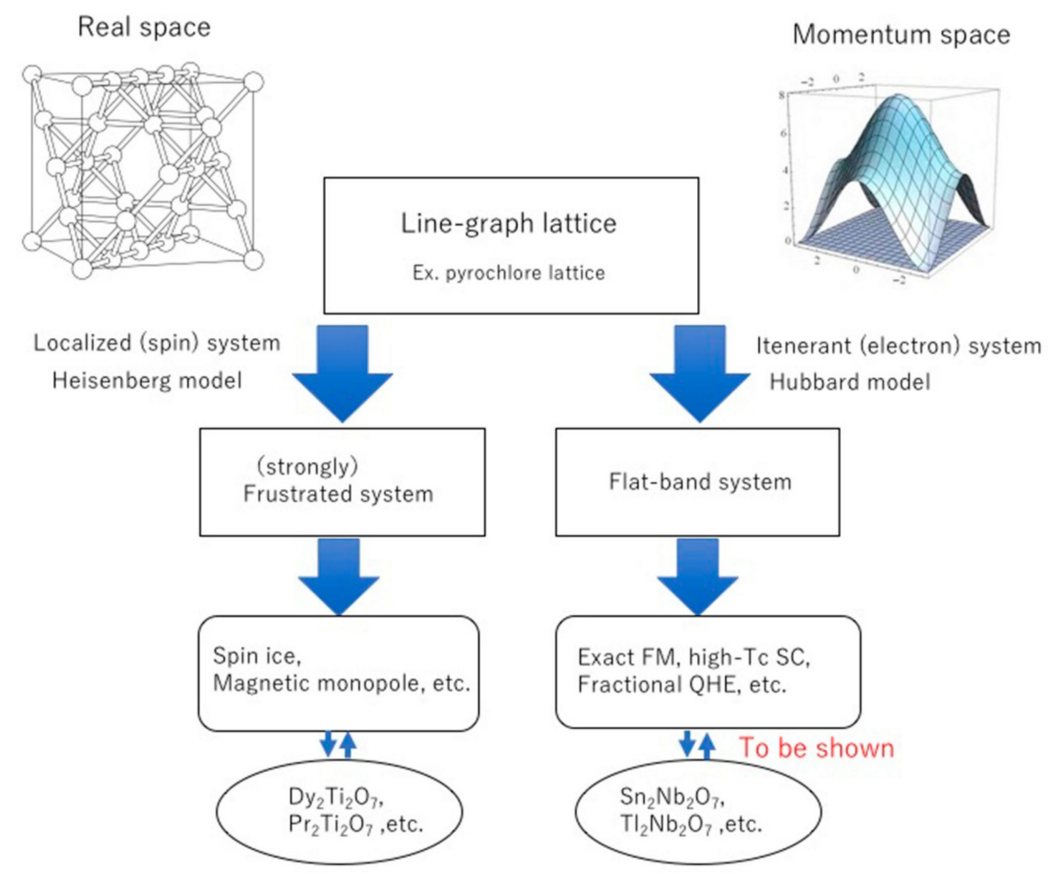

Figure 1. Schematic correspondence between the localized system and the itinerant system.

In our previous study [28], we proposed a guiding principle to obtain FB near the Fermi level $\left(E_{\mathrm{F}}\right)$. The point was to use "s2" ions, in other words, the ions that had two electrons on the outermost s-orbitals. For example, $\mathrm{Sn}^{2+}, \mathrm{Tl}^{1+}$, and $\mathrm{Bi}^{3+}$ are all $\mathrm{s} 2$ ions. The recipe is very simple: (1) Put the s2 ions on the pyrochlore A-site; (2) Fill other sites by closed-shell ions by keeping charge neutrality (e.g., $\mathrm{Sn}^{2+}{ }_{2} \mathrm{Nb}^{5+}{ }_{2} \mathrm{O}^{2-}{ }_{7}$ ); and (3) Calculate the band structure and check whether FB is found or not. There are many candidates with FB chosen by steps (1) and (2), but we have shown that only the $(+2,+5)$ type, i.e., $\mathrm{A}^{2+}{ }_{2} \mathrm{~B}^{5+}{ }_{2} \mathrm{O}^{2-}{ }_{7}$ may exhibit clear (i.e., without being masked by other bands) FB [28]. Due to the large DOS at the top of the valence band, these compounds may show a ferromagnetic ground state when some holes are doped [28,29].

Here, we considered the situation of the "s1" counterpart. Namely, the relevant outermost s-orbital of the A-site is half-filled, in other words, occupied by one electron per site. For example; $\mathrm{Tl}^{2+}, \mathrm{Pb}^{3+}$, and $\mathrm{Bi}^{4+}$ are all s1 ions. This situation has been discussed in the context of the valence skipper [30-32]. The high-temperature superconductivity of $\mathrm{Ba}\left(\mathrm{Pb}_{1-\mathrm{x}} \mathrm{Bi}_{\mathrm{x}}\right) \mathrm{O}_{3}$ and $\left(\mathrm{Ba}_{1-\mathrm{x}} \mathrm{K}_{\mathrm{x}}\right) \mathrm{BiO}_{3}$ has been explained by the valence-skipping mechanism, accompanied with the possible charge order of $\mathrm{s} 0\left(\mathrm{Bi}^{5+}\right)$ and s2 $\left(\mathrm{Bi}^{3+}\right)$ [33-37]. Generally speaking, the s1 state is chemically unstable and splits into s0 and s2 states. In other words, two electrons naturally form a pair and move around. This process effectively generates attractive interaction $U<0$. Actually, the negative- $U$ Hubbard model on a bipartite lattice can lead to s-wave superconductivity [38,39]. However, the negative-U Hubbard model on a frustrated lattice has been much less investigated. In this sense, the $\mathrm{s} 1$ compounds $\mathrm{Tl}_{2} \mathrm{Nb}_{2} \mathrm{O}_{7}$ and $\mathrm{Tl}_{2} \mathrm{Ta}_{2} \mathrm{O}_{7}$ provide good examples, which may realize this interesting situation [40-42]. Unfortunately, they are yet to succeed in metalizing or superconducting $\mathrm{Tl}_{2} \mathrm{Nb}_{2} \mathrm{O}_{7}$. Nevertheless, this direction of research may foresee the manifestation of rich physical properties as above-mentioned. In relation to the s2 system, 
if the underlying band structure is similar, then the s1 system may have a ferromagnetic ground state when the electrons are doped.

In this paper, we demonstrate that the valence bands of six pyrochlore oxides with $\mathrm{A}_{2} \mathrm{~B}_{2} \mathrm{O}_{7}$ $(\mathrm{A}=\mathrm{Sn}, \mathrm{Pb}, \mathrm{Tl} ; \mathrm{B}=\mathrm{Nb}, \mathrm{Ta})$ can be approximately described by the above-mentioned Mielke model. Moreover, we theoretically show that appropriate carrier doping brings about a ferromagnetic ground state, even without magnetic elements. In Section 2, we describe the method of calculation, and in Section 3 we present the results and discussion.

\section{Computational Methods}

We calculated six pyrochlore oxides with $\mathrm{A}_{2} \mathrm{~B}_{2} \mathrm{O}_{7}(\mathrm{~A}=\mathrm{Sn}, \mathrm{Pb}, \mathrm{Tl} ; \mathrm{B}=\mathrm{Nb}$, Ta) from first-principles and used the density-functional theory (DFT) and a full-potential linearized augmented plane wave (FLAPW) scheme (WIEN2k code [43]). The exchange-correlation potential was constructed within the generalized gradient approximation [44]. In Section 3.2, the results are shown for the exchange-correlation potential with local density approximation (LDA) [45]. The parameter $R K_{\max }$ was chosen to be 7.0. The $k$-point mesh was taken so that the total number of the mesh in the first Brillouin zone was about 1000. For simplicity, we assumed that they all had an ideal $\mathrm{A}_{2} \mathrm{~B}_{2} \mathrm{O}_{6} \mathrm{O}^{\prime}$ pyrochlore structure with the space group Fd-3m (\#227). Since oxygen atoms occupy two crystallographic sites, we named them $\mathrm{O}$ and $\mathrm{O}^{\prime}$ to distinguish between them. The atomic position was $\mathrm{A}(0,0,0), \mathrm{B}(1 / 2,1 / 2,1 / 2)$, $\mathrm{O}(u, 1 / 8,1 / 8)$, and $\mathrm{O}^{\prime}(1 / 8,1 / 8,1 / 8)$. We optimized parameter $u$ by minimizing the Hellmann-Feynman force, and the convergence of the atomic position was judged by the Hellmann-Feynman force working on each atom, which was less than 1.0 mRy/a.u. Regarding $\mathrm{Tl}_{2} \mathrm{Ta}_{2} \mathrm{O}_{7}$, we also optimized the lattice constant $a$. The optimized value $a=10.716 \AA$ agreed well with an experimental value $a=10.56 \AA$ [46] or $10.651 \AA$ [47]. For the other five compounds, we used the experimental lattice constant.

Since these compounds have a quasi-FB near $E_{\mathrm{F}}$, we also performed spin-polarized calculations for doped compounds. For the s2 (s1) compounds, we required hole (electron) doping in order to obtain the magnetic ground state. We chose $\mathrm{A}_{2} \mathrm{~B}_{2} \mathrm{O}_{6} \mathrm{~N}$ for s2 compounds $(\mathrm{A}=\mathrm{Sn}, \mathrm{Pb})$, and $\mathrm{A}_{2} \mathrm{~B}_{2} \mathrm{O}_{6} \mathrm{~F}$ for $\mathrm{s} 1$ compounds $(\mathrm{A}=\mathrm{Tl})$.

\section{Results and Discussion}

\subsection{Band Structure and Quasi Flat Band}

Figure 2 shows the band structure of $\mathrm{A}_{2} \mathrm{Nb}_{2} \mathrm{O}_{7}(\mathrm{~A}=\mathrm{Pb}$ and $\mathrm{Tl})$. These looked similar to each other, and our previous results for $\mathrm{Sn}_{2} \mathrm{Nb}_{2} \mathrm{O}_{7}$ also showed a similar band structure [29]. This shows that their electronic structure is described by a unified manner. A quasi-FB was found at the top of the valence band in $\mathrm{Sn}_{2} \mathrm{Nb}_{2} \mathrm{O}_{7}$ and $\mathrm{Pb}_{2} \mathrm{Nb}_{2} \mathrm{O}_{7}$, while its bandwidth was different $\left(\sim 0.4 \mathrm{eV}\right.$ for $\mathrm{Sn}_{2} \mathrm{Nb}_{2} \mathrm{O}_{7}$ and $\sim 0.2$ $\mathrm{eV}$ for $\mathrm{Pb}_{2} \mathrm{Nb}_{2} \mathrm{O}_{7}$ ). Since $\mathrm{Tl}_{2} \mathrm{Nb}_{2} \mathrm{O}_{7}$ has one less electron per formula unit than $\mathrm{Pb}_{2} \mathrm{Nb}_{2} \mathrm{O}_{7}$, this quasi-FB becomes unoccupied and $E_{\mathrm{F}}$ lies just below this quasi-FB. The left panel shows the band structure of the Mielke model. Although this model includes only one adjustable parameter $(t)$, its agreement with the band structure of the real compound $\mathrm{Pb}_{2} \mathrm{Nb}_{2} \mathrm{O}_{7}$ was quite impressive. In the case of the Mielke model shown in Figure 2a, the FB was doubly degenerated. In real $\mathrm{A}_{2} \mathrm{Nb}_{2} \mathrm{O}_{7}$, the degeneracy is partly lifted, but this energy splitting is almost negligible. The density of states analysis showed that this quasi-FB was mainly composed of A-s and $\mathrm{O}^{\prime}-\mathrm{p}$ orbitals. The $\mathrm{Nb}-\mathrm{d}$ orbitals formed a conduction band and were not relevant for this study. 


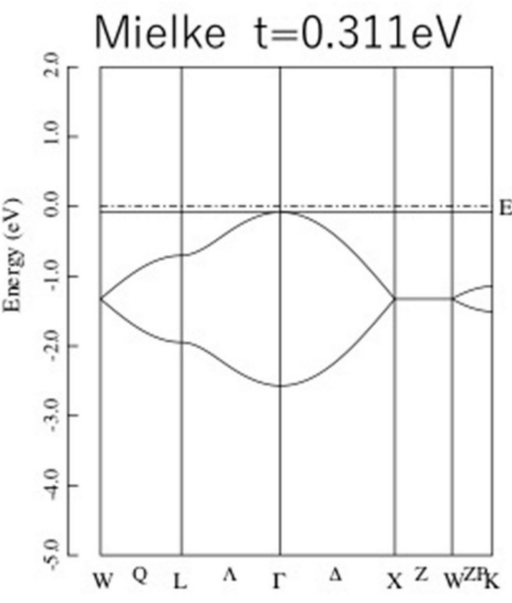

(a)

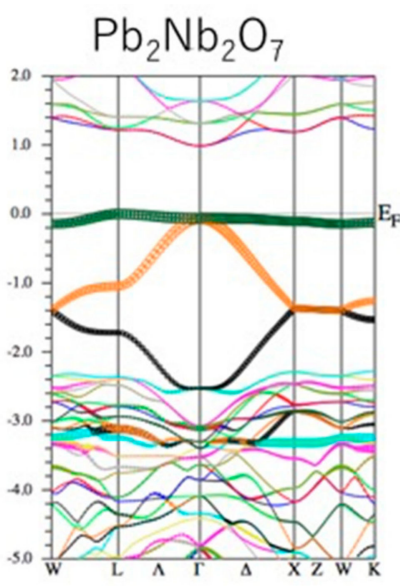

(b)

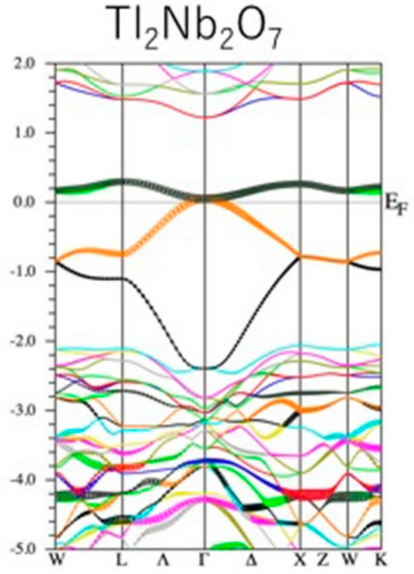

(c)

Figure 2. (a) Energy band of the Mielke model with $t=0.311 \mathrm{eV}$. (b) Band structure of $\mathrm{Pb}_{2} \mathrm{Nb}_{2} \mathrm{O}_{7}$ and (c) $\mathrm{Tl}_{2} \mathrm{Nb}_{2} \mathrm{O}_{7}$. The spin-orbit interaction is not included. The unit of the vertical axis is $\mathrm{eV}$.

The band structure of $\mathrm{A}_{2} \mathrm{Ta}_{2} \mathrm{O}_{7}$ was essentially similar to its $\mathrm{Nb}$ counterpart except for the magnitude of the band gap between the A-s band and $\mathrm{Nb} / \mathrm{Ta}-\mathrm{d}$ band. Since the Ta-d orbital was higher than $\mathrm{Nb}-\mathrm{d}$ in energy, the band gap of $\mathrm{A}_{2} \mathrm{Ta}_{2} \mathrm{O}_{7}$ was $0.5-0.7 \mathrm{eV}$ larger than its $\mathrm{Nb}$ counterpart.

\subsection{Ferromagnetic State}

It is known that the Mielke model of Equation (1) has a unique ferromagnetic ground state if any non-vanishing value of the on-site Coulomb interaction (Hubbard $U$ ) is imposed when the FB is half-filled [23,24]. In the case of a more realistic model including the next nearest neighbor transfer $t^{\prime}$, the exact solution is unknown. However, there has been a numerical study for the 2D checkerboard lattice model that also has a FB when merely $t$ is considered [47]. This shows that the ferromagnetic ground state is still stable when the width of the quasi-FB is smaller than $U$. This result gives an interesting possibility that even a small $U$ in a "nonmagnetic" element such as $\mathrm{Sn}$ and O can induce ferromagnetism. We performed a spin-polarized first-principles calculation for the hole-doped s2 compounds $\mathrm{A}_{2} \mathrm{~B}_{2} \mathrm{O}_{6} \mathrm{~N}(\mathrm{~A}=\mathrm{Sn}, \mathrm{Pb})$ and the electron-doped s1 compounds $\mathrm{A}_{2} \mathrm{~B}_{2} \mathrm{O}_{6} \mathrm{~F}(\mathrm{~A}=\mathrm{Tl})$.

Table 1 shows the calculated magnetic moment of $\mathrm{A}_{2} \mathrm{~B}_{2} \mathrm{O}_{6} \mathrm{X}(\mathrm{X}=\mathrm{N}, \mathrm{F})$ per primitive unit cell. Since the primitive unit cell of the pyrochlore structure contains four $\mathrm{A}$ atoms, the relevant part of the valence band can be described by the Mielke model including four A-s orbitals. All of the compounds in Table 1 have two holes in the valence band, which means that the doubly degenerated quasi-FB is half-filled. Therefore, if the bandwidth of the quasi-FB is smaller than the exchange splitting, it gives the perfect spin polarization with the magnetic moment $M=2.0 \mu_{\mathrm{B}}$. From Table 1, we can see that this condition is satisfied for hole-doped s2 compounds. On the other hand, hole-doped $\mathrm{Tl}$ (s1) compounds have a smaller magnetic moment. This is partly due to the smaller exchange splitting in the $\mathrm{Tl}$ system, and partly due to the larger modification of the quasi-FB with respect to the anion substitution in the Tl system. 
Table 1. Magnetic moment per primitive unit cell (i.e., two formula units) obtained by our first-principles calculation. We show the results for GGA. The lattice constant $a$ was set to the value of the "mother compound". For example, we used the $a$ of $\mathrm{Sn}_{2} \mathrm{Nb}_{2} \mathrm{O}_{7}$ for $\mathrm{Sn}_{2} \mathrm{Nb}_{2} \mathrm{O}_{6} \mathrm{~N}$.

\begin{tabular}{cc}
\hline Compound & Magnetic Moment $\left(\mu_{\text {B cell })}\right.$ \\
\hline $\mathrm{Sn}_{2} \mathrm{Nb}_{2} \mathrm{O}_{6} \mathrm{~N}$ & 2.000 \\
$\mathrm{Sn}_{2} \mathrm{Ta}_{2} \mathrm{O}_{6} \mathrm{~N}$ & 2.001 \\
$\mathrm{~Pb}_{2} \mathrm{Nb}_{2} \mathrm{O}_{6} \mathrm{~N}$ & 2.001 \\
$\mathrm{~Pb}_{2} \mathrm{Ta}_{2} \mathrm{O}_{6} \mathrm{~N}$ & 2.000 \\
$\mathrm{Tl}_{2} \mathrm{Nb}_{2} \mathrm{O}_{6} \mathrm{~F}$ & 1.522 \\
$\mathrm{Tl}_{2} \mathrm{Ta}_{2} \mathrm{O}_{6} \mathrm{~F}$ & 1.507 \\
\hline
\end{tabular}

To see this situation more clearly, we present the band structure of $\mathrm{Pb}_{2} \mathrm{Ta}_{2} \mathrm{O}_{6} \mathrm{~N}$ and $\mathrm{Tl}_{2} \mathrm{Nb}_{2} \mathrm{O}_{6} \mathrm{~F}$ in Figure 3. In $\mathrm{Pb}_{2} \mathrm{Ta}_{2} \mathrm{O}_{6} \mathrm{~N}$, the effect of substituting $\mathrm{N}$ for $\mathrm{O}$ was not especially large. The shape of the valence band was mostly retained, however, in $\mathrm{Tl}_{2} \mathrm{Nb}_{2} \mathrm{O}_{6} \mathrm{~F}$, replacing $\mathrm{O}$ with $\mathrm{F}$ resulted in a very large change in the band structure. This may be explained as follows: $\mathrm{N}$ is more covalent than $\mathrm{O}$ and $\mathrm{F}$, and will be closer to $\mathrm{N}^{2-}$ than $\mathrm{N}^{3-}$. On the other hand, $\mathrm{O}$ and $\mathrm{F}$ are mostly ionic and can be written as $\mathrm{O}^{2-}$ and $\mathrm{F}^{-}$. As a result, the electrostatic potential felt on the A site may not be so different when $\mathrm{O}$ is substituted by $\mathrm{N}$, but will be significantly different when $\mathrm{O}$ is substituted by $\mathrm{F}$. This "rigid-band" situation is also observed in a system where $\mathrm{Sn}_{2} \mathrm{Ta}_{2} \mathrm{O}_{7}$ is doped with $\mathrm{N}$ [29].

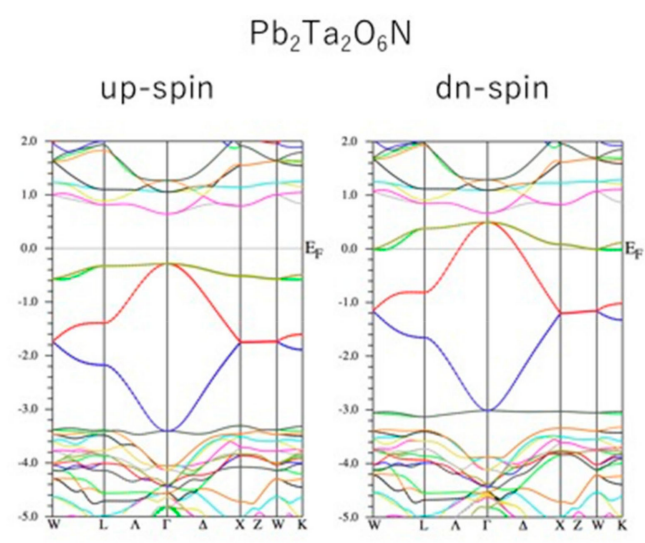

(a)

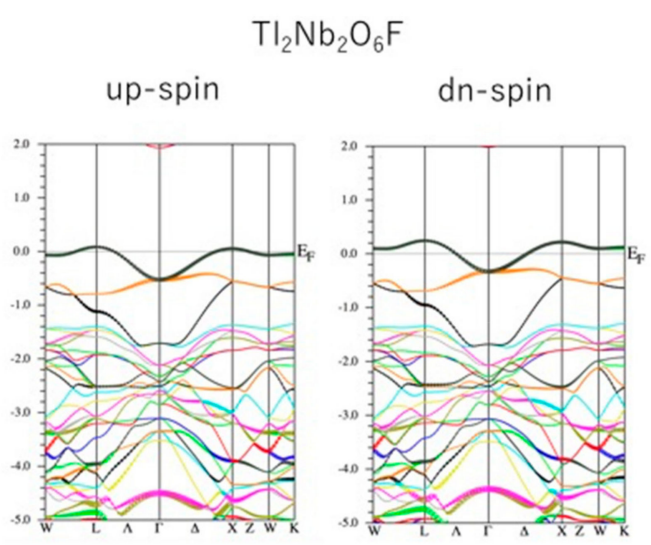

(b)

Figure 3. Spin-dependent band structure of (a) $\mathrm{Pb}_{2} \mathrm{Ta}_{2} \mathrm{O}_{6} \mathrm{~N}$ and (b) $\mathrm{Tl}_{2} \mathrm{Nb}_{2} \mathrm{O}_{6} \mathrm{~F}$. The unit of the vertical axis is $\mathrm{eV}$.

It is known that the existence of ferromagnetism is especially sensitive to the choice of the approximation for the exchange-correlation potential, and to the value of the lattice constant $a[48,49]$. Therefore, we further performed LDA calculations and compared them with the GGA results for $\mathrm{Pb}_{2} \mathrm{Ta}_{2} \mathrm{O}_{6} \mathrm{~N}$ and $\mathrm{Tl}_{2} \mathrm{Ta}_{2} \mathrm{O}_{6} \mathrm{~F}$. We also changed $a$ and calculated $M$ for each $a$ where the results are shown in Figure 4. As for $\mathrm{Pb}_{2} \mathrm{Ta}_{2} \mathrm{O}_{6} \mathrm{~N}$, we can see that LDA and GGA had almost the same $M$ for each $a$. We found that $M=2.00$ for all $a$, which shows that $M$ was "saturated", i.e., the up-spin FB was completely filled and the down-spin FB was empty. On the other hand, in $\mathrm{Tl}_{2} \mathrm{Ta}_{2} \mathrm{O}_{6} \mathrm{~F}$, both the up-spin band and the down-spin band were partially filled so the magnetic moment had a fractional value. M(LDA) is smaller than $M($ GGA), which agrees with the general trend for itinerant ferromagnetism $[48,49]$. The equilibrium value of $a$ for LDA was smaller than that for GGA, which also agrees with the general trend. We could see that the $a$ dependence of $M(a)$ was almost negligible for all of these cases. In other words, the obtained magnetic moment was almost constant by applying pressure at least up to $10 \mathrm{GPa}$. 


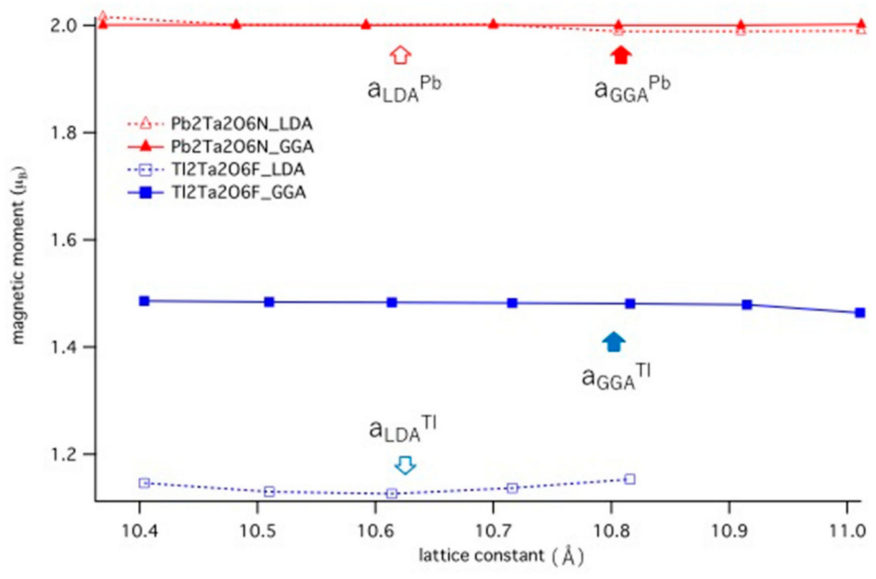

Figure 4. Calculated magnetic moment of $\mathrm{Pb}_{2} \mathrm{Ta}_{2} \mathrm{O}_{6} \mathrm{~N}$ (triangles) and $\mathrm{Tl}_{2} \mathrm{Ta}_{2} \mathrm{O}_{6} \mathrm{~F}$ (squares). Open markers are for LDA, and filled markers are for GGA. The arrows show the equilibrium lattice constant.

\subsection{Comparison with Experimental Results}

We also predicted the ferromagnetic ground state for hole (electron) doped s2 (s1) pyrochlore oxides $\mathrm{A}_{2} \mathrm{~B}_{2} \mathrm{O}_{7}$. Experimentally, small amounts of holes can be doped into $\mathrm{Sn}_{2} \mathrm{Nb}_{2} \mathrm{O}_{7}$ and $\mathrm{Sn}_{2} \mathrm{Ta}_{2} \mathrm{O}_{7}$ [50]. However, the ferromagnetic signal has not been reported in the hole doped sample yet. Photoemission spectra of this sample did not show the sharp peak predicted by the expected FB. Møssbauer spectroscopy revealed that this sample had a large amount of Sn deficiency [51]. This deficiency may greatly affect $\mathrm{FB}$, and it is expected that a less Sn-deficient sample may cause unusual magnetic properties. As for $\mathrm{Pb}_{2} \mathrm{Nb}_{2} \mathrm{O}_{7}$, there was controversy as to whether it was ferroelectric or not, and many crystal structures with lower symmetry have been proposed [52]. However, the lattice instability in the high-symmetry phase mostly occurs in the insulating phase, and an appropriate carrier doping (if possible) may restore the high-symmetry cubic pyrochlore structure. As for $\mathrm{Tl}_{2} \mathrm{Nb}_{2} \mathrm{O}_{6+x}$, the crystal structure is retained as a cubic pyrochlore structure with varying oxygen content $x$. However, metallic samples have not been obtained yet $[40,41]$. Introducing sufficient numbers of itinerant carriers is a crucial key to realizing this unusual magnetism, which does not essentially include a magnetic element.

When we compare the theory and the experiment, we must take into account the many factors that are not included in the theory. Stoichiometry and oxygen deficiency are also crucial parameters for electronic and magnetic properties in "conventional" magnetic oxides [5-10]. The finite size effect due to the sample surface and grain boundary also needs to be considered. All these points are future tasks.

\section{Conclusions}

We found six pyrochlore oxides $\mathrm{A}_{2} \mathrm{~B}_{2} \mathrm{O}_{7}$ with a quasi flat-band at the top of the valence band. The band dispersion was approximately described by the non-interacting Mielke model. We predict that appropriate carrier doping may induce a ferromagnetic ground state, though they do not contain a magnetic element. Essentially, this ferromagnetic state comes from the high density of states of the quasi flat-band.

In order to realize this "d- and f- orbital free" novel magnetism, we must proceed from both theoretical and experimental points of view. Theoretically, there is the desire to go beyond DFT by including the many-body effect. The calculation for the finite temperature is also needed. How to handle randomness such as the oxygen deficiency that cannot be avoided in actual samples is also a future subject of research. In "conventional" localized d-electron magnetic oxides, randomness often induces the spin-glass behavior [5-10]. However, we do not know whether or not spin-glass behavior occurs in the flat band system. Regarding ferromagnetism, the smaller the randomness, the better. Therefore, it will be an experimental challenge to synthesize a crystal with good quality. 
Author Contributions: Conceptualization, I.H.; Methodology, I.H. and T.Y.; Software, I.H. and T.Y.; Validation, I.H., T.Y., and K.K.; Formal analysis, I.H.; Investigation, I.H.; Data curation, I.H.; Writing-original draft preparation, I.H.; Writing-review and editing, T.Y. and K.K.; Visualization, I.H.; Project administration, I.H.; Funding acquisition, I.H. and K.K.

Funding: This research was funded by the Japan Society for the Promotion of Science, grant number 19 K03731.

Acknowledgments: The authors would like to thank Y. Higashi, M. Suzuki, Y. Yanagi. and H. Aoki for the fruitful discussions that took place.

Conflicts of Interest: The authors declare no conflict of interest.

\section{References}

1. Pullar, R.C. Hexagonal Ferrites: A Review of the Synthesis, Properties and Applications of Hexaferrite Ceramics. Prog. Mater. Sci. 2012, 57, 1191-1334. [CrossRef]

2. Almessiere, M.A.; Slimani, Y.; Güngüne, H.; Baykal, A.; Trukhanov, S.V.; Trukhanov, A.V. Manganese/Yttrium Codoped Strontium Nanohexaferrites: Evaluation of Magnetic Susceptibility and Møssbbauer Spectra. Nanomaterials 2019, 24, 18. [CrossRef] [PubMed]

3. Almessiere, M.A.; Slimani, Y.; El Sayed, H.S.; Baykal, A.; Ercan, I. Microstructural and Magnetic Investigation of Vanadium-Substituted Sr-nanohexaferrite. J. Magn. Magn. Mater. 2019, 471, 124-132. [CrossRef]

4. Goodenough, J.B. Electronic and Ionic Transport Properties and Other Physical Aspects of Perovskites. Rep. Prog. Phys. 2004, 67, 1915. [CrossRef]

5. Trukhanov, S.V.; Troyanchuk, I.O.; Fita, I.M.; Szymczak, H.; Bärner, K. Comparative Study of the Magnetic and Electrical Properties of $\operatorname{Pr}_{1-\mathrm{x}} \mathrm{Ba}_{\mathrm{x}} \mathrm{MnO}_{3-\delta}$ Manganites Depending on the Preparation Conditions. J. Magn. Magn. Mater. 2001, 237, 276-282. [CrossRef]

6. Trukhanov, S.V.; Trukhanov, A.V.; Vasiliev, A.N.; Szymczak, H. Frustrated Exchange Interactions Formation at Low Temperatures and High Hydrostatic Pressures in $\mathrm{La}_{0.70} \mathrm{Sr}_{0.30} \mathrm{MnO}_{2.85}$. JETP 2010, 111, $209-214$. [CrossRef]

7. Trukhanov, S.V.; Lobanovski, L.S.; Bushinsky, M.V.; Troyanchuk, I.O.; Szymczak, H. Magnetic Phase Transitions in the Anion-Deficient $\mathrm{La}_{1-\mathrm{x}} \mathrm{Ba}_{x} \mathrm{MnO}_{3-\mathrm{x} / 2}(0 \leq \mathrm{x} \leq 0.50)$ Manganites. J. Phys. Condens. Mater. 2003, 15, 1783-1795. [CrossRef]

8. Trukhanov, S.V.; Trukhanov, A.V.; Vasiliev, A.N.; Balagurov, A.M.; Szymczak, H. Magnetic State of the Structural Separated Anion-Deficient $\mathrm{La}_{0.70} \mathrm{Sr}_{0.30} \mathrm{MnO}_{2.85}$ Manganite. JETP 2011, 113, 819-825. [CrossRef]

9. Trukhanov, S.V.; Trukhanov, A.V.; Szymczak, H.; Botez, C.E.; Adair, A. Magnetotransport Properties and Mechanism of the A-site Ordering in the Nd-Ba Optimal-Doped Manganites. J. Low Temp. Phys. 2007, 149, 185-199. [CrossRef]

10. Doroshev, V.D.; Borodin, V.A.; Kamenev, V.I.; Mazur, A.S.; Tarasenko, T.N.; Tovstolytkin, A.I.; Trukhanov, S.V. Self-Doped Lanthanum Manganites as a Phase-Separated System: Transformation of Magnetic Resonance, and Transport Properties with Doping and Hydrostatic Compression. J. Appl. Phys. 2008, 104, 093909. [CrossRef]

11. Subramanian, M.A.; Aravamudan, G.; Subba Rao, G.V. Oxides Pyrochlore-A Review. Prog. Solid State Chem. 1983, 15, 55-143. [CrossRef]

12. Gardner, J.S.; Gingras, M.J.P.; Greedan, J.E. Magnetic Pyrochlore Oxides. Rev. Mod. Phys. 2010, 82, 53. [CrossRef]

13. Ramirez, A.P. Strongly Geometrically Frustrated Magnets. Annu. Rev. Mater. Sci. 1994, 24, 453-480. [CrossRef]

14. Canals, B.; Lacriox, C. Pyrochlore Antiferromagnet: A Three-Dimensional Quantum Spin Liquid. Phys. Rev. Lett. 1998, 80, 2933. [CrossRef]

15. Ramirez, A.P.; Hayashi, A.; Cava, R.J.; Siddharthan, R.; Shastry, B.S. Zero-Point Entropy in 'Spin Ice'. Nature (London) 1999, 399, 333-335. [CrossRef]

16. Castelnovo, C.; Moessner, R.; Sondhi, S. Magnetic Monopoles in Spin Ice. Nature (London) 2007, 451, 42-45. [CrossRef]

17. Kadowaki, H.; Doi, N.; Aoki, Y.; Tabata, Y.; Sato, T.J.; Lynn, J.W.; Matsuhira, K.; Hiroi, Z. Observation of Magnetic Monopoles in Spin Ice. J. Phys. Soc. Jpn. 2009, 78, 103706. [CrossRef] 
18. Hanawa, M.; Muraoka, Y.; Tayama, T.; Sakakibara, T.; Yamaura, J.; Hiroi, Z. Superconductivity at $1 \mathrm{~K}$ in $\mathrm{Cd}_{2} \operatorname{Re}_{2} \mathrm{O}_{7}$. Phys. Rev. Lett. 2001, 87, 187001. [CrossRef]

19. Hiroi, Z.; Yamaura, J.; Kobayashi, C.T.; Matsubayashi, Y.; Hirai, D. Pyrochlore Oxide Superconductor $\mathrm{Cd}_{2} \operatorname{Re}_{2} \mathrm{O}_{7}$ Revisited. J. Phys. Sco. Jpn. 2018, 87, 024702. [CrossRef]

20. Guo, H.-M.; Franz, M. Three Dimensional Topological Insulators on the Pyrochlore Lattice. Phys. Rev. Lett. 2009, 103, 206805. [CrossRef]

21. Liu, Z.; Liu, F.; Wu, Y.-S. Exotic Electronic States in the World of Flat Bands: From Theory to Material. Chin. Phys. Lett. B 2014, 23, 077308. [CrossRef]

22. Derzhko, O.; Richter, J.; Maksymenko, M. Strongly Correlated Flat Band Systems: The Route from Heisenberg Spins to Hubbard Electrons. Int. J. Mod. Phys. B 2015, 29, 1530007. [CrossRef]

23. Mielke, A. Ferromagnetic Ground States for the Hubbard model on the Line Graphs. J. Phys. A Math. Gen. 1991, 24, L73. [CrossRef]

24. Mielke, A. Ferromagnetism in the Hubbard model on Line Graphs and Further Considerations. J. Phys. A Math. Gen. 1991, 24, 3311. [CrossRef]

25. Kobayashi, K.; Okumura, M.; Yamada, S.; Machida, M.; Aoki, H. Superconductivity in Repulsively Interacting Fermion on a Diamond Chain: Flat-Band Induced Pairing. Phys. Rev. B 2016, 94, 214501. [CrossRef]

26. Hatsugai, $\mathrm{Y}$;; Maruyama, I. $\mathrm{Z}_{\mathrm{Q}}$ Topological Invariants in Polyacetylene, Kagome, and Pyrochlore Lattice. Europhys. Lett. 2011, 95, 20003. [CrossRef]

27. Wang, Y.; Yao, H.; Gu, Z.; Gong, C.; Sheng, D.-N. Non-Abelian Quantum Hall Effect in Topological Flat Band. Phys. Rev. Lett. 2012, 108, 126805. [CrossRef] [PubMed]

28. Hase, I.; Yanagisawa, T.; Kawashima, K. Computational Design of Flat Band System. Nanoscale Res. Lett. 2018, 13, 63. [CrossRef] [PubMed]

29. Hase, I.; Yanagisawa, T.; Aiura, Y.; Kawashima, K. Possibility of Flat-Band Ferromagnetism in Hold-Doped Pyrochlore Oxides $\mathrm{Sn}_{2} \mathrm{Nb}_{2} \mathrm{O}_{7}$ and $\mathrm{Sn}_{2} \mathrm{Ta}_{2} \mathrm{O}_{7}$. Phys. Rev. Lett. 2018, 120, 196401. [CrossRef]

30. Anderson, P.W. Model for the Electronic Structure of Amorphous Semiconductors. Phys. Rev. Lett. 1975, 34, 953-955. [CrossRef]

31. Dzero, M.; Schmalian, J. Superconductivity in Charge Kondo System. Phys. Rev. Lett. 2005, 941, 157003. [CrossRef] [PubMed]

32. Matsushita, Y.; Bluhm, H.; Geballe, T.H.; Fisher, I.R. Evidence of Charge Kondo Effect in Superconducting Tl-Doped PbTe. Phys. Rev. Lett. 1988, 61, 2713-2716. [CrossRef] [PubMed]

33. Taraphder, A.; Krishnamurthy, H.R.; Pandit, R.; Ramakrishnan, T.V. Negative-U Extended Hubbard Model for Doped Barium Bismathates. Phys. Rev. B 1981, 52, 1368. [CrossRef]

34. Varma, C.M. Missing Valence States, Diamagnetic Insulators, and Superconductors. Phys. Rev. Lett. 1988, 61, 2713-2716. [CrossRef] [PubMed]

35. Hase, I.; Tanagisawa, T. Madelung Energy of the Valence-Skipping Compound $\mathrm{BaBiO}_{3}$. Phys. Rev. B 2007, 76, 174103. [CrossRef]

36. Hase, I.; Tanagisawa, T. Electronic States of Valence-Skipping Compounds. J. Phys. Conf. Ser. 2008, 108, 012011. [CrossRef]

37. Sleight, A.W. Valency, Valence Degeneracy, Ferroelectricity and Superconductivity. Prog. Solid State Chem. 2009, 37, 251-261. [CrossRef]

38. Micnas, R.; Ranninger, D.; Robaszkievicz. Superconductivity in Narrow-Band Systems with local Nonretarded Attractive Interaction. Rev. Mod. Phys. 1990, 62, 113-171. [CrossRef]

39. Moreo, A.; Scalapino, D.J. Two-Dimensional Negative-U Hubbard Model. Phys. Rev. Lett. 1991, 66, $946-948$. [CrossRef]

40. Mizoguchi, H.; Kawazoe, H.; Ueda, T.; Hayashi, S.; Hosono, H.; Ueda, N. Formation and Optical Absorbtion Spectra of Mixed Valence State of $\mathrm{Tl}$ in $\mathrm{Tl}_{2} \mathrm{Nb}_{2} \mathrm{O}_{6+x}$ with Pyrochlore Structure. Bull. Chem. Soc. Jpn. 1996, 69, 111-115. [CrossRef]

41. Fourquet, J.L.; Duroy, H.; Lacorre, $\mathrm{P} . \mathrm{Tl}_{2} \mathrm{Nb}_{2} \mathrm{O}_{6+\mathrm{x}}(0 \leqq \mathrm{x} \leqq 1)$ : A Continuous Cubic Pyrochlore Type Solid Solution. J. Solid State Chem. 1995, 114, 575-584. [CrossRef]

42. Ramadass, N.; Palanisamy, N.; Gopalakrishnan, J.; Aravamudan, G.; Sastri, M.V.C. Some $\mathrm{ABO}_{3} \mathrm{Oxides}$ with Defect Pyrochlore Structure. Solid State Commun. 1975, 17, 545-575. [CrossRef]

43. Blaha, P.; Schwarz, K.; Madsen, G.K.H.; Kvasnicka, D.; Luitz, J. WIEN2k, an Augmented Plane Wave + local orbitals Program for Calculating Crystal Properties; Vienna Univ. of Technology: Vienna, Austria, 2001. 
44. Perdew, J.P.; Burke, K.; Ernzerhof, M. Generalized Gradient Approximation Made Simple. Phys. Rev. Lett. 1996, 77, 3875. [CrossRef] [PubMed]

45. Perdew, J.P.; Wang, Y. Accurate and Simple Analytic Representation of the Electron-Gas Correlation. Phys. Rev. B 1992, 45, 13244. [CrossRef]

46. Belyaev, I.N.; Lupeiko, T.G.; Nalbandyan, V.B.; Abanina, E.V. Exchange Reactions in Systems Comprising Alkali Metal, Silver, and Thallium Sulphates, Niobates, and Tantalates. Russ. J. Inorg. Chem. 1978, 23, 18-22.

47. Kusakabe, K.; Aoki, H. Robustness of the Ferromagnetism of in Flat Band. Phys. (Amst.) B 1994, 194-195, 215-216. [CrossRef]

48. Soulairol, R.; Fu, C.-C.; Barreteau, C. Structure and Magnetism of Bulk Fe and Cr: From Plane Waves to LCAO methods. J. Phys. Condens. Matter 2010, 22, 295502. [CrossRef]

49. Friak, M.; Sob, M.; Vitek, V. Ab-initio Calculation of Phase Boundaries in Iron along the BCC-FCC Transformation Path. Phys. Rev. B 2001, 63, 052405. [CrossRef]

50. Kikuchi, N.; Samizo, A.; Ikeda, S.; Aiura, Y.; Mibu, K.; Nishio, K. Carrier Generation in a p-type Oxide Semiconductor $\mathrm{Sn} 2\left(\mathrm{Nb}_{2-\mathrm{x}} \mathrm{Ta}_{\mathrm{x}}\right) \mathrm{O}_{7}$. Phys. Rev. Mater. 2017, 1, 021601R. [CrossRef]

51. Aiura, Y.; Ozawa, K.; Hase, I.; Bando, K.; Haga, H.; Kawanaka, H.; Samizo, A.; Kikuchi, N.; Mase, K. Disappearance of Localized Valence Bond Maximum in Ternary Tin Oxide with Pyrochlore Structure, $\mathrm{Sn}_{2} \mathrm{Nb}_{2} \mathrm{O}_{7}$. J. Phys. Chem. C 2017, 121, 9480-9488. [CrossRef]

52. Ubic, R.; Reaney, I.M. Structure and Dielectric Properties of Lead Pyrochlores. J. Am. Ceram. Soc. 2012, 85, 2472-2478. [CrossRef]

(C) 2019 by the authors. Licensee MDPI, Basel, Switzerland. This article is an open access article distributed under the terms and conditions of the Creative Commons Attribution (CC BY) license (http://creativecommons.org/licenses/by/4.0/). 